\title{
Effects of Attractiveness and Social Status on Dating Desire in Heterosexual Adolescents: An Experimental Study
}

\author{
Thao Ha $\cdot$ Geertjan Overbeek $\cdot$ Rutger C. M. E. Engels
}

Received: 14 May 2008/Revised: 17 March 2009/ Accepted: 12 September 2009/Published online: 15 October 2009

(C) The Author(s) 2009. This article is published with open access at Springerlink.com

\begin{abstract}
The present study examined to what extent adolescent dating desire is based on attractiveness and social status of a potential short-term partner. Further, we tested whether selfperceived mate value moderated the relationship between dating desire and attractiveness of a potential partner. Data were used from a sample of 1,913 adolescents aged 13-18. Participants rated the importance of various characteristics of a potential partner and also participated in an experimental vignette study in which dating desire was measured with either low or high attractive potential partners having either a high or low social status. The results showed that boys rated attractiveness as more important than girls, while social status was rated as relatively unimportant by both sexes. In addition, in the experimental vignette study, it was found that attractiveness was the primary factor for boys' dating desire. Only when a potential partner was attractive, social status became important for boys' dating desire. For girls, on the other hand, it appeared that both attractiveness and social status of a potential partner were important for their dating desire. Finally, boys and girls who perceived themselves as having a high mate value showed more dating desire toward an attractive potential partner compared to adolescents who perceived themselves as having a low mate value. The present results extend previous research by showing that attractiveness of a potential partner is important to both adolescent boys and girls, but social status does not strongly affect dating desire during this particular age period.
\end{abstract}

T. Ha $(\bowtie) \cdot$ G. Overbeek · R. C. M. E. Engels

Behavioural Science Institute, Radboud University Nijmegen, POB 9104, 6500 HE Nijmegen, The Netherlands

e-mail: T.Ha@bsi.ru.nl

Present Address:

G. Overbeek

Department of Developmental Psychology, Utrecht University, Utrecht, The Netherlands
Keywords Adolescents · Dating desire $\cdot$ Status · Attractiveness $\cdot$ Sexual strategies theory

\section{Introduction}

Evolutionary psychologists propose that men and women have different strategies that underlie short-term mating. ${ }^{1}$ According to the sexual strategies theory (SST; Buss \& Schmitt, 1993), men and women have different mate preferences since the levels of parental investment in offspring are higher for women than for men (Feingold, 1992; Trivers, 1972). While women invest nine months in pregnancies and even more years to raise their offspring (e.g., lactation and care), men do not have these responsibilities. Consequently, the benefits of short-term mating differ for men and women. The main benefit of short-term mating for men is that it maximizes their number of sexual mates and therefore their number of offspring (Schmitt et al., 2003; Schmitt, Shackelford, \& Buss, 2001). Benefits of short-term mating for women are more complex, but scholars generally assume that women endeavor to gain access to high quality genes (Gangestad \& Thornhill, 1997) and attempt to acquire immediate resources, such as food, jewelry, and fashionable clothes. These may be the indicators that in case of pregnancy the mate will be able to provide the resources for a safe upbringing of offspring (Buss \& Schmitt, 1993; Greiling \& Buss, 2000).

SST holds that in order to maximize the number of healthy offspring, men are primarily driven by the attractiveness of a

\footnotetext{
${ }^{1}$ Extensive literature exists about long-term mating and important mate characteristics of long-term mates. However, the present study focused on adolescent dating desire and is, therefore, framed within the context of short-term mating. For more information on long-term mating, see Gangestad and Simpson (2000).
} 
potential mate, since attractiveness is assumed to be an indicator of "good genes" in terms of good health and high reproductive value (Barber, 1995; Gangestad, Thornhill, \& Yeo, 1994; Thornhill \& Grammer, 1999). In the case of short-term mating, attractiveness might also be an important cue for women, as it increases the likelihood of healthy offspring if the short-term mating behavior led to pregnancy or if a short-term mate became a long-term mate (Gangestad \& Simpson, 1990). Since females' levels of parental investment are high in the case of a pregnancy, attracting a mate with a high social status might also be important for short-term mating. In support of the SST, studies showed that attractive features of a potential short-term mate were essential for both men and women (Buunk, Dijkstra, Fetchenhauer, \& Kenrick, 2002; Li \& Kenrick, 2006; Sprecher \& Regan, 2002; Wiederman \& Dubois, 1998) and social status is particularly important for women (Buss \& Schmitt, 1993; Townsend \& Wasserman, 1998; Wiederman \& Dubois, 1998).

Although previous studies provided valuable knowledge on short-term mate preferences, most studies reviewed here exclusively relied on questionnaires in which respondents explicitly rated the importance of various characteristics. These answers could be biased by social desirability and might not measure actual influences of mate preferences. Therefore, direct self-reports might primarily tap into general beliefs about short-term relationships rather than one's own individual mate preference (Feingold, 1990; Fletcher \& Kininmonth, 1992). In other words, whether the same pattern of results can be found if the importance of attractiveness and social status of a potential mate are manipulated in a experimental design remains to be investigated (DeSteno, Bartlett, Braverman, \& Salovey, 2002; Schmitt, Couden, \& Baker, 2001). To overcome this limitation, we applied an experimental vignette study in which we also provided visual stimuli to enhance external validity (Townsend \& Wasserman, 1998).

So far, the vast majority of empirical research focusing on SST has been conducted with adults. However, the first steps on the mating market are made — in most Western societies — during the teenage years (Connolly, Furman, \& Konarski, 2000; Neemann, Hubbard, \& Masten, 1995). Moreover, it is during these years that the human brain undergoes maturational changes that lead to many profound physical changes, such as the development of breasts in girls and the growth of facial hair in boys (Spear, 2000). These biological and physical changes are accompanied by psychological changes, such as an increasing interest in relationships with opposite-sex peers and sexual fantasies, which also stimulate the development of active sexual strategies in adolescents (Buss, 1995). It is essential to gain more knowledge on the sexual strategies that underlie adolescents' dating desire, since several differences exist in terms of relationship goals and orientations between adolescents and adults that might be linked to differences in sexual strategies and reasons for partner choices (Collins, 2003). Unlike many adult relationships, adolescent's intimate relationships are characterized by a much shorter duration and a general lack of a "future" orientation. Consequently, dating goals and desire may be different for adolescents than for adults. For adolescents, for example, dating might primarily be a context in which one experiments with sexual experiences as such (Feiring, 1996).

Despite the fact that adolescent relationships differ from adult relationships, only a few empirical studies have focused on teenagers' partner preferences. Therefore, the present study aims to investigate adolescents' dating desires based on attractiveness and social status of a potential short-term partner. In the present study, attractiveness was defined as the global attractiveness of a potential short-term partner for a date. Previous studies showed that attractiveness of a potential short-term partner was rated as highly important by both boys and girls (Regan \& Joshi, 2003). More specifically, others suggested that a partners' attractiveness might be-as in adults - more significant to boys than girls (Dunkel, 2005; Feiring, 1996). However, no support has been found for social status as an important determinant of adolescents' dating desire (Feiring, 1996; Regan \& Joshi, 2003). Nevertheless, Eyre, Read, and Millstein (1997) found that, compared to girls, boys reported using more dating strategies that emphasized spending of money, which might serve as an indicator of high social status for girls. Thus, although it is known that adult women prefer partners with a high social status, it is unclear whether it is important for adolescent girls as well.

In addition to sex differences, within-sex variations in the use of sexual strategies may also be important, despite the fact that such variations have received less attention both theoretically and empirically (Buss \& Schmitt, 1993; Gangestad \& Simpson, 2000). According to SST, it depends on one's own mate value whether a preferred sexual strategy can be realized (Buss \& Schmitt, 1993). It could be that somebody prefers a partner who is highly attractive and has a high social status, but that one's own mate value is not high enough to attract that particular partner. In that case, in order to increase mating success, one should lower one's standards and settle for a partner who is lower in attractiveness and/or social status. Indeed, support was found for this "matching principle" as people tend to select mates who are more alike in terms of attractiveness and social status (Berscheid, Dion, Walster, \& Walster, 1971; Byrne, Clore, \& Smeaton, 1986; Jones et al., 2005; Van Straaten, Engels, Finkenauer, \& Holland, 2008). The few empirical studies that examined the role of self-perceived mate value in the context of short-term mating provided some preliminary evidence that self-perceived mate value was related to the specific types of sexual strategies adults engage in (Landolt, Lalumière, \& Quinsey, 1995; Van Straaten et al., 2008). Nonetheless, the key difference between adults and adolescents is the widely varying nature of adolescents' relationship experience. In the Netherlands, $35 \%$ of the adolescents in the age range of $12-$ 18 reported to have none or very little relationship experience 
(Overbeek, 2006). Possibly, because adolescents do not have much experience with different sexual strategies, they are less skilled in estimating which partners they can attract. Consequently, they may aim for the best partner possible in terms of both attractiveness and social status.

The present study aimed to extend previous research by investigating adolescents' dating desires based on attractiveness and social status of a potential short-term partner. We investigated this question based on (1) data from survey questions about their partner preferences and (2) data from an experimental vignette study. Based on SST premises, we first hypothesized that attractiveness of a potential short-term partner was important for both boys' and girls' dating desire. Second, we hypothesized that girls would show a preference for a short-term partner with a high social status and that, on the contrary, social status was not important for boys' dating desire. More specifically, we expected that social status would only become important for boys' partner preference if a potential short-term partner was attractive and for girls, social status would be important irrespective of attractiveness of a potential short-term partner. Importantly, we scrutinized these hypotheses controlling for potential confounder effects of variation in relationship experiences and current relationship status. Finally, we tested the potential moderator effects of self-perceived mate value on adolescents' desire to date with an attractive person. We hypothesized that boys' and girls' preference for attractive and high social status persons would be independent of their own perceived mate value.

\section{Method}

\section{Participants}

The total sample consisted of 1,913 adolescents (930 male, 983 female) between 13 and 18 years old $(M=15.34, S D=$ .80). All adolescents taking part in the study were enrolled in average or higher-level education (i.e., preparatory college and pre-university education). In this sample, 380 (19.9\%) adolescents defined themselves as currently involved in a heterosexual relationship. In the original sample, five adolescents were involved in homosexual relationships. Due to the very small number, and to perform the analyses on only heterosexual participants, they were omitted from further analyses. In total, 393 (20.5\%) adolescents were currently not involved in a relationship and never had a relationship before. The remaining 1,140 (59.6\%) adolescents were also currently not involved in a relationship but did have previous relationship experience. The majority of the relationships (74.2\%) lasted between 1 and 6 months. More girls $(n=$ $240,62.3 \%$ ) than boys ( $n=140,37.7 \%$ ) were currently involved in romantic relationships $\left(\chi^{2}=23.44, p<.001\right)$.
Design and Procedure

We randomly selected 17 secondary schools in the Netherlands, which were sent an introductory letter and who were contacted by telephone shortly after. Seven schools were unable to participate in the study due to difficulties with fitting the study in their time and/or exam schedules; in total, 10 schools agreed to participate. Classroom assessments were conducted from January to March 2007. Data of the current study were collected as part of a broader survey on social skills and general dating behaviors. We received approval for conducting the present study of the ethical committee of the Faculty of Social Sciences, Radboud University of Nijmegen. Before the onset of the study, information about the study was sent to parents. Parents could refuse to give consent for participation of their child in the study and two explicit refusals of parents were recorded. All pupils consented to participation in the study. Further, all pupils were ensured that their information would not be given to any third party (e.g., teachers or parents) and they were seated separately during the assessment to secure their privacy. Next to the female researcher or a female research assistant one teacher was present during the assessments. The teacher, however, was instructed to keep a low profile during the assessment and only responded to questions if adolescents specifically asked for their teacher. During the assessment, pupils were not allowed to discuss their answers with other pupils. The questionnaires were administered during regular school hours and lasted no more than $50 \mathrm{~min}$ (i.e., the regular duration of one class). Part of the questionnaire was the vignette experiment, which had to be completed at the beginning of the questionnaire. Other items in the questionnaires were completed after the vignette part.

Adolescents were randomly given either attractive or less attractive pictures of a person of the opposite sex. Above the pictures, a description of either a high or low social status person was provided. We used photographs of faces of attractive and less attractive adolescent boys and girls, which were selected from various sites on the internet, among which websites of modeling agencies. During the selection of the pictures, we carefully matched the pictures on various picture characteristics, such as picture quality, angle of picture, and framing. The two most attractive and the two least attractive pictures were selected for ratings by an "expert panel," who rated the pictures in terms of overall attractiveness. Our panel of experts consisted of 59 adolescents ( 26 boys, 33 girls) in the same age group as the adolescents from the present sample - between 13 and 18 years old. These adolescents rated the four photographs on a 7-point overall attractiveness scale. The order in which the panel viewed the photographs was balanced, so no order effects could bias the outcome. Paired $t$-tests showed that the picture of the less attractive girl was rated by boys as significantly less attractive than the picture of the more attractive girl: $t(25)=13.12, p<$ $.001 ; \mathrm{M}_{\text {less attractive }}=1.81(S D=0.80), \mathrm{M}_{\text {more attractive }}=5.38$ 
$(S D=1.10)$. Similarly, girls rated the picture of the less attractive boy as significantly less attractive than the picture of the more attractive boy: $t(32)=14.92, p<.001 ; \mathrm{M}_{\text {less attractive }}=$ $2.52(S D=0.97), \mathrm{M}_{\text {more attractive }}=5.27(S D=0.76)$.

Regarding the manipulation of social status, the description of either high or low social status was provided together with the attractive or less attractive picture. These descriptions were adapted from a previous experimental study and were known to successfully discriminate between high and low social status (Van Straaten et al., 2008). In the present study, the high social status person was enrolled in the highest education program in the Netherlands, had more upper-class hobbies (i.e., skiing and tennis), had a father whose profession was "professor of European history," a mother who was a lawyer with her own practice, and whose ambition was to become the "best in his/her field of work." The low social status person was enrolled in the lowest education level in the Netherlands, had no hobbies but liked to hang out with friends, had a father whose profession was not known because this person had never met his/her father, had a mother who worked part-time in a supermarket, who did not know what his/her ambitions were, and found it unimportant to have any ambitions. Adolescents with a relationship were asked to answer the questions as if they were not having a relationship.
Measures

Importance of Personal Characteristics of a Partner

The questionnaire we used to assess participants' self-rated importance of various partner characteristics (Buss, 1989) consisted of 21 items, focusing, among other things, on whether a partner should have an attractive appearance or should be ambitious (see Table 1). Adolescents were asked to rate the importance of each characteristic of a potential future partner on a 10-point scale ranging from 1 (not important at all) to 10 (very important).

\section{Dating Desire}

Adolescents' dating desire was measured with the question "This person is new in town. (S)he does not know many people. Would you like to go out on a date with him/her?" Responses were provided on a 7-point scale ranging from 1 (absolutely not) to 7 (absolutely). Furthermore, we asked "How attractive do you find this person, based on the picture?" and "How appealing do you find the description of this person?" Both questions could be answered on the same 7-point scale.

Table 1 Independent $t$-tests for importance of characteristics for potential partners by sex

\begin{tabular}{|c|c|c|c|c|c|c|}
\hline & \multicolumn{2}{|l|}{ Boys } & \multicolumn{2}{|l|}{ Girls } & \multirow[t]{2}{*}{$t$} & \multirow[t]{2}{*}{$p$} \\
\hline & $M$ & $S D$ & $M$ (ordering) & $S D$ & & \\
\hline 1. Reliable & 9.13 & 1.06 & $9.61(1)$ & .72 & 11.53 & .00 \\
\hline 2. Honest & 9.10 & 1.03 & $9.54(2)$ & .79 & 10.39 & .00 \\
\hline 3. Kind & 8.79 & 1.11 & $9.25(3)$ & .88 & 9.92 & .00 \\
\hline 4. Attractive appearance & 8.30 & 1.40 & $7.50(10)$ & 1.53 & 11.93 & .00 \\
\hline 5. Healthy & 8.10 & 1.92 & $7.75(8)$ & 1.99 & 3.75 & .00 \\
\hline 6. Sense of humor & 7.99 & 1.37 & $8.43(4)$ & 1.23 & 7.40 & .00 \\
\hline 7. Can go along with friends & 7.87 & 1.77 & $8.15(7)$ & 1.49 & 3.78 & .00 \\
\hline 8. Interesting personality & 7.85 & 1.58 & $8.33(6)$ & 1.36 & 7.09 & .00 \\
\hline 9. Caring & 7.83 & 1.43 & $8.43(5)$ & 1.20 & 9.86 & .00 \\
\hline 10. Romantic & 7.20 & 1.68 & $7.68(9)$ & 1.55 & 6.59 & .00 \\
\hline 11. Flexible & 7.08 & 1.49 & $7.30(11)$ & 1.35 & 3.36 & .00 \\
\hline 12. Intelligent & 6.99 & 1.87 & $6.99(12)$ & 1.85 & $<1$ & $\mathrm{~ns}$ \\
\hline 13. Ambitious & 6.68 & 1.70 & $6.93(13)$ & 1.74 & 3.16 & .00 \\
\hline 14. Easygoing & 6.64 & 2.08 & $6.10(15)$ & 1.97 & 5.86 & .00 \\
\hline 15. Finished education & 6.18 & 2.57 & $6.61(14)$ & 2.43 & 3.74 & .00 \\
\hline 16. Creative & 6.12 & 2.09 & $6.03(16)$ & 2.03 & $<1$ & ns \\
\hline 17. Wants to have children in future & 5.67 & 2.57 & $5.76(17)$ & 2.73 & $<1$ & $\mathrm{~ns}$ \\
\hline 18. High salary & 5.59 & 2.79 & $5.69(18)$ & 2.52 & $<1$ & ns \\
\hline 19. Good family background & 5.57 & 3.03 & $5.26(19)$ & 2.71 & 2.32 & .02 \\
\hline 20. Has experiences with relationships & 4.84 & 2.44 & $4.44(20)$ & 2.25 & 3.70 & .00 \\
\hline 21. Religious & 2.81 & 2.40 & $2.90(21)$ & 2.38 & $<1$ & ns \\
\hline
\end{tabular}

Note: The numbers in parentheses for girls refer to their rank ordering of each of the 21 characteristics. For boys, their rank ordering is as given in the left column of Table 1 . Due to Bonferroni correction, values are significant at $\alpha=.05 / 21 \approx .002$ or lower 


\section{Relationship Status and Experience}

Adolescents' relationship status was assessed, that is, whether they were currently involved in a relationship or not. Relationship experience was measured in terms of how many relationships the participant had ever been involved in.

\section{Self-perceived Mate Value (SPMV)}

This concept was assessed with the Self-Perceived Mating Success Scale (Landolt et al., 1995), which contains 10 items measuring the extent to which an individual believes s/he can attract mates of the opposite sex. Examples of items are "Members of the opposite sex notice me" and "Members of the opposite sex are attracted to me." Responses were given on a 7-point scale ranging from 1 (strongly disagree) to 7 (strongly agree). Cronbach's alpha was .90. An exploratory factor analyses (principal component analysis with VARIMAX rotation) was performed to investigate whether different factors arose for boys' and girls' scores on SPMV. It appeared that the same factors arose for boys and girls.

\section{Results}

\section{Importance of Personal Characteristics of a Partner}

To investigate which characteristics of a potential future partner were important for adolescents, $t$-tests were conducted to test sex differences. Table 1 shows that both boys and girls reported that reliability, honesty, and kindness were the three most important characteristics for a potential partner. Girls, however, generally rated these characteristics as more important than boys. A strong sex difference was found in terms of attractiveness, which was rated as the fourth most important characteristic by boys and only as the tenth most important characteristic by girls. Concerning social status, both boys and girls attached relatively little importance to the characteristics ambitious, finished education, high salary, and good family background. However, girls rated the characteristics ambitious and finished education as significantly more important than boys. There were no significant sex differences for high salary and good family background.

\section{Manipulation Checks for Attractiveness and Social Status}

On average, girls $(M=3.37, S D=1.81)$ reported more dating desire than boys $(M=3.04, S D=1.97), t(1865)=3.72, \eta_{\mathrm{p}}^{2}=$ $.01, p<.001$. For the attractiveness manipulation, a $t$-test revealed that boys rated, on average, the attractive person as more attractive $(M=4.17, S D=1.67)$ than the less attractive person $(M=2.19, S D=1.67), t(903)=18.11, \eta_{\mathrm{p}}^{2}=.26, p<.001$.
On average, girls also rated the attractive person as more attractive $(M=4.28, S D=1.73)$ than the less attractive person $(M=2.07, S D=1.38), t(941)=21.98, \eta_{\mathrm{p}}^{2}=.33, p<.001$. Concerning the manipulation of social status, boys rated, on average, the vignettes depicting persons with high social status as having a higher social status $(M=3.42, S D=1.70)$ than the ones depicting persons with lower social status $(M=2.78$, $S D=1.73) t(925)=5.57, \eta_{\mathrm{p}}^{2}=.03, p<.001$. On average, girls also rated the vignettes depicting persons with high social status as having a higher social status $(M=3.75, S D=1.65)$ than the ones depicting persons with lower social status $(M=2.42, S D=1.56), t(976)=12.88, \eta_{\mathrm{p}}^{2}=.15, p<.001$.

\section{Dating Desire: Attractiveness and Social Status}

In order to examine whether dating desire was related to attractiveness and social status, a 2 (Attractiveness: Attractive versus Unattractive) $\times 2$ (Social Status: High versus Low) ANCOVA was performed separately for boys and girls. Dating desire was the dependent variable and age, relationship status, and previous relationship experience were included as covariates. Mean ratings for dating desire of boys and girls for the different conditions are shown in Table 2 and test results for boys and girls are reported in Table 3.

For boys, the potential confounder relationship status was not significantly related to dating desire. In contrast, age and relationship experience were significantly related to dating desire, indicating that boys who were older and had more relationship experience reported more dating desire. After controlling for these variables, the significant main effects of attractiveness and social status were qualified by the interaction effect of attractiveness x social status. Post hoc comparisons (Bonferroni) showed that dating desire in the unattractive condition did not differ for high or low social status $F(1,502)<1$. In contrast, in the high attractive condition, boys showed more dating desire when the other person had a high social status, $F(1,423)=$ $10.45, \eta_{\mathrm{p}}^{2}=.02, p<.01$.

For girls, the potential confounders age, relationship status, and previous relationship experience were not significantly related to dating desire. After controlling for these variables, significant main effects of attractiveness and social status were found, indicating that girls showed more dating desire in the attractive and in the high social status condition.

\section{Self-perceived Mate Value as Moderator}

Again, a 2 (Attractiveness: Attractive versus Unattractive) $\times 2$ (Social Status: High versus Low) ANCOVA was conducted separately for boys and girls. Dating desire was the dependent variable and age, relationship status, and previous relationship experience were included as covariates. This time, however, self-perceived mate value (SPMV) was included in the models as a moderator. 
Table 2 Means and SDs of dating desire for sex on condition (attractiveness and social status)

\begin{tabular}{|c|c|c|c|c|c|c|}
\hline \multirow[t]{2}{*}{ Condition } & \multicolumn{2}{|c|}{ Boys $(n=930)$} & \multicolumn{2}{|c|}{ Girls $(n=983)$} & \multicolumn{2}{|c|}{ Combined $(n=1,913)$} \\
\hline & $M$ & $S D$ & $M$ & $S D$ & $M$ & $S D$ \\
\hline \multicolumn{7}{|l|}{ Low attractiveness } \\
\hline Low social status & 1.78 & 1.11 & 2.10 & 1.56 & 1.93 & 1.14 \\
\hline High social status & 1.80 & 1.08 & 2.43 & 1.25 & 2.12 & 1.21 \\
\hline Combined & 1.79 & 1.09 & 2.27 & 1.22 & 2.03 & 1.18 \\
\hline \multicolumn{7}{|l|}{ High attractiveness } \\
\hline Low social status & 4.26 & 1.79 & 4.13 & 1.75 & 4.18 & 1.76 \\
\hline High social status & 4.81 & 1.65 & 4.76 & 1.49 & 4.78 & 1.57 \\
\hline Combined & 4.53 & 1.74 & 4.43 & 1.66 & 4.48 & 1.70 \\
\hline
\end{tabular}

Note: Data for groups of low and high social status are presented within the low and high attractiveness conditions. The "combined" categories in the rows of Table 2 refer to the overall scores within low and high attractiveness conditions for both sexes separately, whereas the "combined" categories in the column of Table 2 refer to the overall scores in the low and high attractiveness conditions for the total sample

Table 3 ANCOVA of dating desire on attractiveness and social status

\begin{tabular}{|c|c|c|c|c|c|c|c|c|}
\hline & \multicolumn{4}{|c|}{ Boys } & \multicolumn{4}{|c|}{ Girls } \\
\hline & df & $F$ & Effect size & $p$ & df & $F$ & Effect size & $p$ \\
\hline \multicolumn{9}{|l|}{ Covariates } \\
\hline Age & 1 & 10.47 & .01 & .001 & 1 & $<1$ & .00 & ns \\
\hline Relationship status & 1 & $<1$ & .00 & ns & 1 & 2.42 & .00 & ns \\
\hline Relationship experience & 1 & 3.92 & .00 & .048 & 1 & 1.42 & .00 & ns \\
\hline \multicolumn{9}{|l|}{ Main effects } \\
\hline Attractiveness & 1 & 846.55 & .49 & .000 & 1 & 551.94 & .37 & .000 \\
\hline Social status & 1 & 4.66 & .01 & .031 & 1 & 27.42 & .03 & .000 \\
\hline \multicolumn{9}{|l|}{ Interaction } \\
\hline Attractiveness $\times$ social status & 1 & 9.08 & .01 & .003 & 1 & 2.20 & .00 & ns \\
\hline
\end{tabular}

For boys, no significant effects were found for the control variables relationship status and relationship experience. In contrast, age was significant related to dating desire, $F(1,889)=$ $10.83, \eta_{\mathrm{p}}^{2}=.01, p<.001$. After controlling for these variables, the significant main effects of attractiveness, social status, and SPMV were qualified by the interaction effects of attractiveness $\times$ social status, $F(1,889)=10.38, \eta_{\mathrm{p}}^{2}=.01, p<.01$, and SPMV $\times$ Attractiveness, $F(1,889)=18.52, \eta_{\mathrm{p}}^{2}=.02$, $p<.001$. Post hoc comparisons (Bonferroni) showed that dating desire in the unattractive condition did not differ for high or low social status, $F(1,502)<1$. In contrast, in the high attractive condition, boys showed more dating desire when the other person had a high social status, $F(1,423)=10.45, \eta_{\mathrm{p}}^{2}=.02$, $p<.01$. Further, post hoc comparisons (Bonferroni) showed that dating desire in the unattractive condition did not differ for high or low SPMV, $F(1,500)<1$. In contrast, in the high attractive condition, boys showed more dating desire when they perceived themselves as having a high mate value as compared to boys who perceived themselves as having a lower mate value, $F(1,423)=14.57, \eta_{\mathrm{p}}^{2}=.03, p<.001$.
For girls, no significant effects were found for the control variables age, relationship status, and relationship experience. After controlling for these variables, the significant main effects of attractiveness and social status were qualified by the interaction effect of SPMV $\times$ attractiveness, $F(1,946)=9.25$, $\eta_{\mathrm{p}}^{2}=.01, p<.01$. Post hoc comparisons (Bonferroni) showed that dating desire in the unattractive condition did not differ for high or low SPMV, $F(1,479)<1$. In contrast, in the high attractive condition, girls showed more dating desire when they perceived themselves as having a high mate value as compared to girls who perceived themselves as having a lower mate value, $F(1,491)=13.86, \eta_{\mathrm{p}}^{2}=.03, p<.001$.

\section{Discussion}

Research on SST has been dominated by studies using young adult samples. The present study aimed to investigate adolescents' dating desire based on attractiveness and social status of a potential partner. When explicitly asked to rate various 
characteristics of a potential partner, boys rated attractiveness as more important than girls. Social status was not very important for both boys and girls. In the experimental vignette part of the study, in which we manipulated attractiveness and social status of a potential partner for a date, support was found for the importance of attractiveness in both boys' and girls' dating desire. Social status was important for boys' dating desire only when the potential partner was attractive. However, social status was important for girls' dating desire in both the attractive and less attractive condition. Finally, we found that self-perceived mate value moderated the relationship between attractiveness and dating desire for both boys and girls. Specifically, adolescents who perceived themselves as having a high mate value showed more dating desire if the other person was attractive compared to adolescents who perceived themselves as having a lower mate value.

The experimental findings were in line with those from previous correlational findings of survey research among adolescents (Feiring, 1996; Regan \& Joshi, 2003), and provide more insight into adolescents' sexual strategies by showing that attractiveness was a strong determinant of dating desire. Moreover, we extended previous research by showing that, if adolescents' partner preferences were measured through an experimental vignette study by providing pictures of potential partners, the importance of attractiveness was even more substantial than was shown in the ratings of various characteristics, and this was especially true for girls. This might imply that previous findings on sexual strategies that were exclusively based on selfreport ratings had underestimated the importance of attractiveness, in particular for girls. Ample studies on adult samples also indicated that both men and women strive for attractive short-term mates (Buunk et al., 2002; Li \& Kenrick, 2006; Sprecher \& Regan, 2002). Our study showed that the tendency to seek attractive partners for short-term mating can also be found in adolescents who are at the beginning of their relationship career and still have little experience with dating.

According to SST, social status would be important for girls' dating desire since this indicates that a specific partner will provide resources and will be able to take care of potential offspring. For boys, on the contrary, social status of the potential partner would be less important due to their minimal parental investment. The present results supported this hypothesized sex difference partly. More specifically, social status appeared to be important for both boys and girls' dating desire. Girls rated the characteristics "ambitious" and "finished education" as significantly more important than boys in the survey. In addition, in the vignette experiment social status was important for girls' dating desire in both the attractive and less attractive condition. For boys, however, social status was important only when the potential partner was attractive. The present results might imply that both social status and attractiveness of a potential short-term partner were primary conditions for girls' dating desire and for boys on the contrary, only attractiveness was a primary condition and social status had an additional value merely when a potential partner was attractive.

Although in comparison to the importance of attractiveness for adolescent dating desire, social status was a minor short-term strategy. Apparently, adolescents do not attach much importance to finding a partner who has a high social status. This may be explained by the fact that, in adolescence, sexual behaviors are just beginning to emerge and adolescents still live at home with parents. Hence, it is possible that social status will become increasingly important during the transition into adulthood, when individuals need to become independent and have to take care of themselves. Moreover, it is not until then when differences between indicators of social status of a potential shortterm partner become clear (e.g., in financial resources and ambitions). An alternative explanation for the finding that social status seemed relatively unimportant to adolescents' dating desire could be that the use of pictures of same-age potential partners prevented sex-specific preferences to emerge. For example, Kenrick, Gabrielidis, Keefe, and Cornelius (1997) showed that, if adolescents were asked who they would ideally date, both boys and girls would prefer older partners. Moreover, it has been shown that girls indeed dated older boys (Connolly et al., 2000). Thus, it could be that sex differences will occur as older potential partners perhaps will elicit the importance of social status.

In line with SST, evidence emerged for the moderating role of self-perceived mate value emerged from our study (see also Landolt et al., 1995; Van Straaten et al., 2008). Our results indicated that adolescents did not generally aim for the best partner possible, but that they choose a partner that fits their own mate value. It is important, however, to interpret this moderator effect in the light of its small effect size. That is, although significant, the moderating effect of self-perceived mate value was rather weak and seems to play only a minor role in the light of the overriding importance of physical attractiveness of a potential partner.

Interestingly, we found that girls generally showed more dating desire compared to boys in the context of short-term mating. This is remarkable given the fact that SST generally assumes that men are more inclined to engage in short-term mating than women (Buss \& Schmitt, 1993; Schmitt, Shackelford et al., 2001). However, the onset of pubertal timing is earlier for girls and therefore girls might be more prone to date compared to same-aged boys in this specific adolescent age group (BrooksGunn \& Reiter, 1990). Indeed, in line with the present study, it has been shown that girls generally start dating at a younger age and have more experience with the sexual aspects of relationships (Alsaker, 1996; Kaltiala-Heino, Kosunen, \& Rimpelä, 2003). Furthermore, girls have larger other-sex friendship networks compared to boys and start developing these friendships at a younger age, which allows the earlier establishment of romantic relationships (Connolly et al., 2000; Feiring, 1999).

Despite the fact that we extended previous studies on SST by means of correlational and experimental paradigms using a 
large adolescent sample, some limitations should be addressed. First of all, we adapted the descriptions of social status from previous research on adults and older adolescents. However, the cues that potential partners display referring to either high or low social status might differ for adolescents and adults. For adults, being highly ambitious is an indicator of high social status. For adolescents, this may be less clear and perhaps other characteristics of potential partners are more accurate to measure social status (e.g., how popular a potential partner is among his peers, and the impression of how willing he is to spend money on dates). Thus, future research is needed to test whether the same results would be found if more appropriate descriptions of social status were provided. In addition, the indicators of the low status condition should be formulated more comparable as in the low status condition the vignette person was fatherless and in the high status condition father had a high social status occupation. Finally, although we used data from questionnaires and from the experimental vignette study, possibly, the adolescent's choice of a "paper" mate may not reflect his/her actual decision when selecting a mate in real life (Kurzban \& Weeden, 2005; Fisman, Iyengar, Kamenica, \& Simonson, 2006). Therefore, future research should use designs that enable analyses of actual partner preferences in real life situations, such as observational experiments that allow the possibility to manipulate the confederate's social status and his/her attractiveness (Van Straaten et al., 2008) or speed dating sessions in which adolescents interact with potential partners in real life (Finkel, Eastwick, \& Matthews, 2007; Todd, Penke, Fasolo, \& Lenton, 2007).

In sum, our findings revealed that the attractiveness of a potential partner is an important factor for adolescents' dating desire, whereas social status seems to be less important. Further, we found support for the association between self-perceived mate value and adolescent dating desire. Adolescents who perceived themselves as having a high mate value showed more dating desire with attractive potential partners compared to adolescents who perceived themselves as having a lower mate value. Therefore, the present results reveal that SST is at least partly applicable to adolescents dating desire, but needs further attention in terms of how social status might be defined in this age group.

Acknowledgements Thao Ha was supported by a Mozaiek grant and Geertjan Overbeek by a VENI grant, both from the Netherlands Organisation for Scientific Research, during the preparation of this article.

Open Access This article is distributed under the terms of the Creative Commons Attribution Noncommercial License which permits any noncommercial use, distribution, and reproduction in any medium, provided the original author(s) and source are credited.

\section{References}

Alsaker, F. D. (1996). The impact of puberty. Journal of Child Psychology and Psychiatry, 37, 249-258.
Barber, N. (1995). The evolutionary psychology of physical attractiveness: Sexual selection and human morphology. Ethology and Sociobiology, 16, 395-424.

Berscheid, E., Dion, K., Walster, E., \& Walster, G. W. (1971). Physical attractiveness and dating choice: A test of the matching hypothesis. Journal of Experimental Social Psychology, 7, 173-189.

Brooks-Gunn, J., \& Reiter, E. O. (1990). The role of pubertal processes. In G. R. Elliott \& S. Feldman (Eds.), At the threshold: The developing adolescent (pp. 16-53). Cambridge: Harvard University Press.

Buss, D. M. (1989). Sex differences in human mate preferences: Evolutionary hypotheses tested in 37 cultures. Behavioral and Brain Sciences, 12, 1-49.

Buss, D. M. (1995). Evolutionary psychology: A new paradigm for psychological science. Psychological Inquiry, 6, 1-30.

Buss, D. M., \& Schmitt, D. P. (1993). Sexual strategies theory: An evolutionary perspective on human mating. Psychological Review, 100, 204-232.

Buunk, B. P., Dijkstra, P., Fetchenhauer, D., \& Kenrick, D. T. (2002). Age and gender differences in mate selection criteria for various involvement levels. Personal Relationships, 9, 271-278.

Byrne, D., Clore, G. L., \& Smeaton, G. (1986). The attraction hypothesis: Do similar attitudes affect anything? Journal of Personality and Social Psychology, 51, 1167-1170.

Collins, A.C. (2003). More than a myth: The developmental significance of romantic relationships during adolescence. Journal of Research on Adolescence, 13, 1-24.

Connolly, J., Furman, W., \& Konarski, R. (2000). The role of peers in the emergence of heterosexual romantic relationships in adolescence. Child Development, 71, 1395-1408.

DeSteno, D., Bartlett, M. Y., Braverman, J., \& Salovey, P. (2002). Sex differences in jealousy: Evolutionary mechanism or artifact of measurement? Journal of Personality and Social Psychology, 83, 11031116.

Dunkel, C. S. (2005). The role of ego-identity status in mating preferences. Adolescence, 40, 489-501.

Eyre, S. L., Read, N., \& Millstein, S. G. (1997). Adolescent sexual strategies. Journal of Adolescent Health, 20, 286-293.

Feingold, A. (1990). Gender differences in effects of physical attractiveness on romantic attraction: A comparison across five research paradigms. Journal of Personality and Social Psychology, 59, 981-993.

Feingold, A. (1992). Gender differences in mate selection preferences: A test of the parental investment model. Psychological Bulletin, 112, $125-139$.

Feiring, C. (1996). Concept of romance in 15-year-old adolescents. Journal of Research on Adolescence, 6, 181-200.

Feiring, C. (1999). Other-sex friendship networks and the development of romantic relationships in adolescence. Journal of Youth and Adolescence, 28, 495-512.

Finkel, E. J., Eastwick, P. W., \& Matthews, J. (2007). Speed-dating as an invaluable tool for studying romantic attraction: A methodological primer. Personal Relationships, 14, 149-166.

Fisman, R., Iyengar, S. S., Kamenica, E., \& Simonson, I. (2006). Gender differences in mate selection: Evidence from a speed dating experiment. Quarterly Journal of Economics, 121, 673-697.

Fletcher, G. J., \& Kininmonth, L. A. (1992). Measuring relationship beliefs: An individual differences scale. Journal of Research in Personality, 26, 371-397.

Gangestad, S. W., \& Simpson, J. A. (1990). Toward an evolutionary history of female sociosexual variation. Journal of Personality, 58 , 69-96.

Gangestad, S. W., \& Simpson, J. A. (2000). The evolution of human mating: Trade-offs and strategic pluralism. Behavioral and Brain Sciences, 23, 573-644.

Gangestad, S. W., \& Thornhill, R. (1997). Human sexual selection and developmental stability. In D. T. Kenrick \& J. A. Simpson (Eds.), 
Evolutionary social psychology (pp. 160-196). Hillsdale, NJ: Lawrence Erlbaum Associates.

Gangestad, S. W., Thornhill, R., \& Yeo, R. A. (1994). Facial attractiveness, developmental stability, and fluctuating asymmetry. Ethology and Sociobiology, 15, 73-85.

Greiling, H., \& Buss, D. M. (2000). Women's sexual strategies: The hidden dimension of extra-pair mating. Personality and Individual Differences, 28, 929-963.

Jones, B. C., Little, A. C., Boothroyd, L., Feinberg, D. R., Cornwell, R. E., DeBruine, L. M., et al. (2005). Women's physical and psychological condition independently predict their preference for apparent health in faces. Evolution and Human Behavior, 26, 451-457.

Kaltiala-Heino, R., Kosunen, E., \& Rimpela, M. (2003). Pubertal timing, sexual behaviour and self-reported depression in middle adolescence. Journal of Adolescence, 26, 531-545.

Kenrick, D. T., Gabrielidis, C., Keefe, R. C., \& Cornelius, J. S. (1996). Adolescents' age preferences for dating partners: Support for an evolutionary model of life-history strategies. Child Development, 67, 1499-1511.

Kurzban, R., \& Weeden, J. (2005). HurryDate: Mate preferences in action. Evolution and Human Behavior, 26, 227-244.

Landolt, M. A., Lalumière, M. L., \& Quinsey, V. L. (1995). Sex differences and intra-sex variations in human mating tactics: An evolutionary approach. Ethology and Sociobiology, 16, 3-23.

Li, N. P., \& Kenrick, D. T. (2006). Sex similarities and differences in preferences for short-term mates: What, whether, and why. Journal of Personality and Social Psychology, 90, 468-489.

Neemann, J., Hubbard, J., \& Masten, A. S. (1995). The changing importance of romantic relationship involvement to competence from late childhood to late adolescence. Development and Psychopathology, 7, 727-750.

Overbeek, G. (2006). [Adolescents' romantic relationships]. Unpublished raw data.

Regan, P. C., \& Joshi, A. (2003). Ideal partner preferences among adolescents. Social Behavior and Personality, 31, 13-20.

Schmitt, D. P., Alcalay, L., Allik, J., Ault, L., Austers, I., Bennett, K. L., et al. (2003). Universal sex differences in the desire for sexual variety: Tests from 52 nations, 6 continents, and 13 islands. Journal of Personality and Social Psychology, 85, 85-104.

Schmitt, D. P., Couden, A., \& Baker, M. (2001). The effects of sex and temporal context on feelings of romantic desire: An experimental evaluation of sexual strategies theory. Personality and Social Psychology Bulletin, 27, 833-847.

Schmitt, D. P., Shackelford, T. K., \& Buss, D. M. (2001). Are men really more "oriented" toward short-term mating than women? Psychology, Evolution \& Gender, 3, 211-239.

Spear, L. P. (2000). The adolescent brain and age-related behavioral manifestations. Neuroscience and Biobehavioral Reviews, 24, 417463.

Sprecher, S., \& Regan, P. C. (2002). Liking some things (in some people) more than others: Partner preferences in romantic relationships and friendships. Journal of Social and Personal Relationships, 19, 463 481.

Thornhill, R., \& Grammer, K. (1999). The body and face of woman: One ornament that signals quality? Evolution of Human Behavior, 21, $105-120$.

Todd, P. M., Penke, L., Fasolo, B., \& Lenton, A. P. (2007). Different cognitive processes underlie human mate choices and mate preferences. Proceedings of the National Academy of Sciences, USA, 104, 15011-15016.

Townsend, J. H., \& Wasserman, T. (1998). Sexual attractiveness: Sex differences in assessment and criteria. Evolution and Human Behavior, 19, 171-191.

Trivers, R. L. (1972). Parental investment and sexual selection. In B. Campbell (Ed.), Sexual selection and the descent of man (pp. 136179). London: Aldine.

Van Straaten, I., Engels, R. C. M. E., Finkenauer, C., \& Holland, R. W. (2008). Sex differences in short-term mate preferences and behavioral mimicry: A semi-naturalistic experiment. Archives of Sexual Behavior, 37, 902-911.

Wiederman, M. W., \& Dubois, S. L. (1998). Evolution and sex differences in preferences for short-term mates: Results from a policy capturing study. Evolution and Human Behavior, 19, 153170. 